\title{
12 Firing Process
}

Due to its irreversibility, most potters consider firing, along with the selection of raw material, as one of the most important stages in the pottery manufacturing process. During firing, important physicochemical changes take place in the ceramics that affect the several components that make up the paste depending on their particular nature. Hence, diverse reactions take place in the paste during the heating process and new minerals can be formed from those that decompose. The final microstructure of the pottery is determined by two basic factors (Cuomo Di Caprio, 1985; Dawson and Kent, 1987; Linares et al., 1983; Livingstone-Smith, 2007; Sillar, 2000; Vázquez, 2003):

a) Paste: The final product obtained after the firing depends on the chemical and mineralogical composition of the clay and tempers that compose the paste. Therefore, the use of different types of raw materials favours a great variability in paste behaviour during this process. Other parameters of the pastes that are involved in the firing process are the homogeneity and particle-size, as well as the compaction and porosity of the walls of the vessel.

b) Pottery firing strategy: the pottery, the oxidiser and fuel are key elements in the firing strategy. The combination of these parameters allows potters to carry out different firing procedures. Other important factors are also the kind of firing structure used and the way the vessels are arranged within the structure. All these factors determine the temperature reached during firing, its duration as well as the heating rate and the firing atmosphere that prevails along the various stages of this phase of the chaîne opératoire.

As already seen, the analysis of pottery firing involves considering a large number of variables that are closely interrelated, but many of them are only partially reflected in the ceramic sherds. To overcome these constraints, we can complement the study of archaeological pottery with ethnographic approaches and experimental research. These disciplines can be used with the aim of approach the several firing possibilities and alternatives available to the potters in order to make hypotheses about the firing strategies used.

Pottery firing strategies are complex and there is not a direct correlation between firing structures, temperatures, duration and fuels. Although there are some general trends, the alternative choices are varied and do not respond to established universal patterns. There are always cases that are out of the ordinary, such as the ceramics used to bake bread in the Balkans. The firing of these vessels takes place in domestic hearths while they are being used to bake bread for the first time. Thus, the ceramic is fired simultaneously with the food it contains (Djordjevic, 2003).

However, linear and simplistic interpretations regarding the pottery firing often prevail. In this way, the maximum firing temperature is usually overestimated while the duration of the procedure and the way it is finished are rarely taken into 
consideration (Gosselain, 1992b; Livingstone-Smith, 2001). It is also very common to associate the use of kilns with wheel-thrown pottery fired at high temperature. However, there are cases in which wheel-made pottery productions are exposed to low temperatures (Livingstone-Smith, 2007). The same prejudices apply to handmade pottery fired, for instance, in open firings. Thus, open firings and pit firings are considered to have low calorific value, however in special conditions they can reach up to $900-1000^{\circ} \mathrm{C}$ (e.g., Maggetti et al., 2011; Waldren, 1991).

In short, the complexity and the wide range of possibilities related to the pottery firing process require of all the data available to best approach this phase of the chaine opératoire. Moreover, researchers have to be also very cautious when different firing procedures are inferred on the basis of a single variable, such as the equivalent firing temperature. This parameter is often too simplistic and, in addition, may not directly reflect the maximum temperature reached during the firing (Gibson and Woods, 1990; Gosselain, 1992b; Livingstone-Smith, 2001; Maggetti et al., 2011; Vázquez, 2003).

The technical and physicochemical complexity involved in the firing process requires a methodology that complements various analytical techniques in order to diagnose, as far as possible, the relationship existing between this phase and the characteristics of the vessels. Thus, the presence of certain components and features in the fabric provides key information to approach the estimated or equivalent firing temperature (Buxeda et al., 1995; Tite, 1969), duration and atmosphere of firing. For example, the degree of porosity and compaction of the fabric is largely related to firing temperature (Cuomo Di Caprio, 1985). In this sense, the changes which take place in the paste due to thermal processes are usually addressed from the combined analysis of the ceramic record by means of petrographic and binocular microscopes, XRD and SEM, among others (e.g., Albero, 2011b). Moreover, chemical analyses are also useful to infer the potential changes in the pastes due to the heating process. For example, thermodynamic triangles (Fig. 12.1) can be used in order to know the high temperature phases $\left(>850^{\circ} \mathrm{C}\right)$ that should be expected in the ceramics according to their chemical composition and the firing temperature (Heimann, 1989).

The changes that take part in the paste as a result of the application of heat can be also approached through artificial re-firings of archaeological samples. These experimental re-firings are usually developed through X-ray diffractometers equipped with a high-temperature chamber or thermal analysis (e.g., Differential Thermal Analysis-DTA, Thermogravimetric Analysis-TGA, Differential Scanning CalorimetryDSC, Dilatometry-DIL). These methods are sometimes used on experimental samples specially created with the aim to record such changes in specific types of clays or pastes. The re-firing of experimental or archaeological samples is often used in ceramic archaeometry to create thermal behavioural patterns that can be subsequently compared with the archaeological record in order to approach the estimated firing temperature of the vessels (Albero, 2010; Mainman, 1982; Tite, 1969).

Accurate estimations of the temperature and duration of the firing in archaeological ceramics are not carried out without constraints. There are problems derived from 
the degree of representation of the section of the pottery studied. In this way, heat is not always uniformly distributed across the ceramic body (Maggetti et al., 2011), thus, the effects of firing can be different in the diverse parts that compose a single vessel. These differences are conditioned by the size of the pottery, the thickness of the walls along the vessel and its position inside the firing structure. This means that samples taken from the body or the base of the ceramics may not exhibit the same characteristics as other parts of the vessels that are usually thinner, such as rims.

In any case, the archaeometric study of sherds allow us to approach the pottery firing procedures by means of the accurate analysis of the vessel's microstructure, the presence of high temperature minerals, the chromatic variations along the section and the degree of alteration and decomposition of certain components of the paste (e.g., carbonates, clay minerals, organic matter, etc.). Moreover, the complementarity existing between the methods discussed permits to interrelate the pottery firing procedures with other technological choices identified in other phases of the chaîne opératoire.

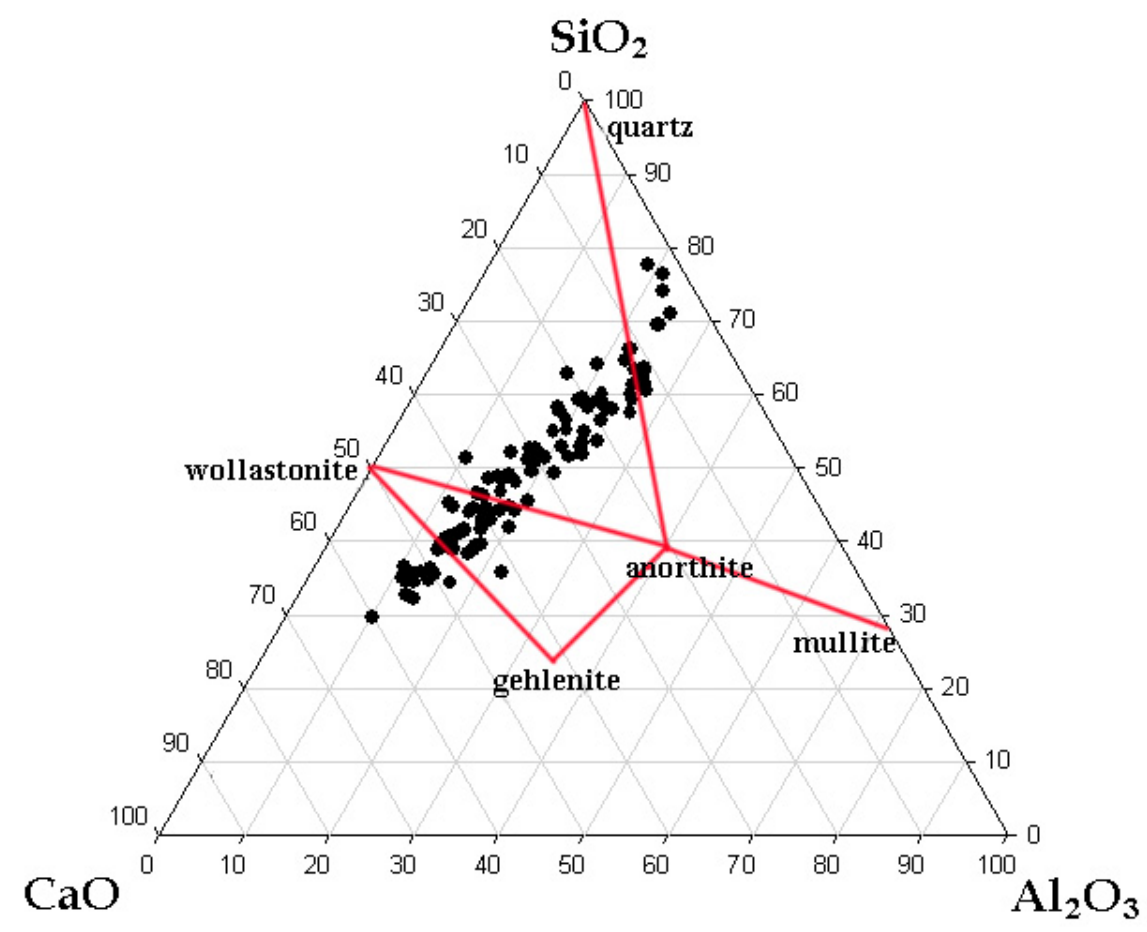

Figure 12.1: Thermodynamic assessment of some pottery samples in a ternary phase diagram of the $\mathrm{CaO}-\mathrm{Al}_{2} \mathrm{O}_{3}-\mathrm{SiO}_{2}$ system. The position of the points is related to the high temperature minerals expected in the vessels depending on their chemical composition and firing temperature. 


\subsection{Changes in the Clay Matrix during the Firing Process}

Once the pottery firing begins the dehydration process already initiated in the paste in the drying phase continues. Thus, the total elimination of the absorbed water in the lamellar structure of the clay takes place at between $50^{\circ}$ and $110^{\circ} \mathrm{C}$, when a quite intense endothermic peak corresponding to the loss of water is recorded by DTA-TGADSC analyses (Albero, 2010; Papadopoulou et al., 2006). The effects that generate this process in the vessel depend on the firing strategy and the pastes used. The pore water trapped in the micro-pores after drying becomes steam during the firing, thus expanding and increasing its volume. If the steam cannot escape from outside the pottery between the clay particles, the rising pressure in the matrix generates energy which may cause the walls of the vessel to chip off (Cuomo Di Caprio, 1985; García Rosselló and Calvo, 2006; Gibson and Woods, 1990).

After the loss of pore water, the constitution water of the clay minerals is progressively removed between $450^{\circ}$ and $800^{\circ} \mathrm{C}$. This wide range of temperature depends on the type of phyllosilicates present in the clay, their crystalline modifications and the firing atmosphere. As takes place in the drying phase, the dehydration of clay minerals causes a significant shrinkage of the walls of the vessel. In this process, aplastic components may play an important role by acting as a skeleton in the paste and providing a more open texture. Thus, inclusions and tempers improve dehydration and heat distribution along the pottery, thus minimising the generation of fractures during the firing process.

At less than $650^{\circ} \mathrm{C}$ endothermic peaks emerge in DTA-TGA analysis related to the rapid decomposition of certain clay minerals such as montmorillonite or kaolinite that dehydroxilate at relatively low temperatures. The low temperature of decomposition of these minerals is the reason why they are rarely documented in archaeological ceramics. Thus, the presence of these clay minerals in the fabrics may be due to two reasons. First, that the firing did not exceed this range of temperature. Second and less probable, that the clay minerals detected relate to postdepositional alterations (Ortega et al. 2005).

In contrast to montmorillonite or kaolinite other clay minerals such as illite are most commonly identified in the archaeological record, since their dehydroxylation occurs at higher temperatures $\left(600^{\circ}-700^{\circ} \mathrm{C}\right)$. Subsequently, the water loss does not affect its structure that is maintained in its anhydrous form up to $850^{\circ}-1000^{\circ} \mathrm{C}$, depending on its degree of crystallization and the firing conditions. Thus, there is not a significant reduction in the weight and volume of the phyllosilicates up to that temperature range. Nevertheless, the persistence of well-preserved illitemuscovite peaks in the XRD diffractograms (Fig. 12.2) provides evidence of low firing temperatures (García Orellana et al., 2001). As with other minerals, phyllosilicates that are present in low fired pottery can be neoformed. Therefore, after a long time, clay minerals can reach their initial structure, providing peak intensities and areas in the XRD diffractograms that are quite similar to their initial state. Thus, the 
presence of well-preserved peaks of clay minerals such as illite-muscovite at $10 \AA$ and, especially, $5 \AA$, provides information regarding this neoformation process. From $650^{\circ} \mathrm{C}$ the diagnostic peak of illite-muscovite is altered and this alteration proceeds if the temperature increases up to the almost total disappearance of the mineral around $800^{\circ}-850^{\circ} \mathrm{C}$ (Drebushchak et al., 2005).

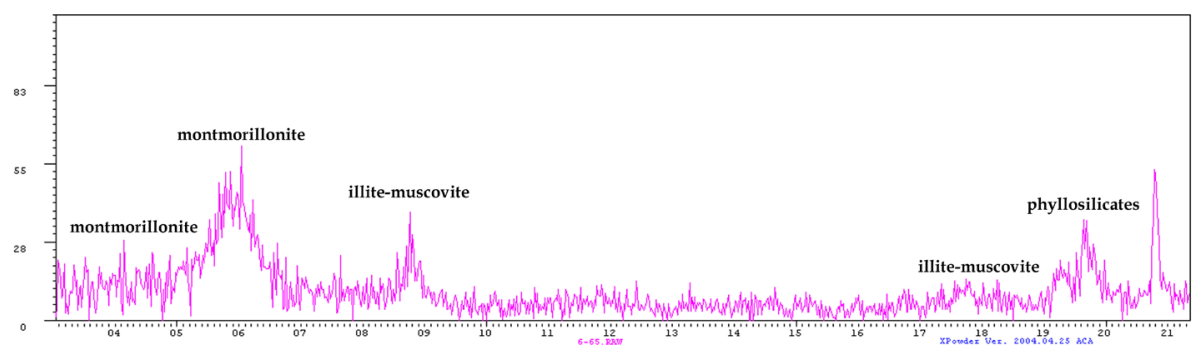

Figure 12.2: XRPD diffractograms showing well-preserved peaks of illite-muscovite and montmorillonite in an archaeological pottery.

When the ceramics have reached temperatures of $550^{\circ}-650^{\circ} \mathrm{C}$ and have certain hardness can be empirically recognised due to their reddish and incandescent appearance inside the firing structure (Palomar, 2005). Thus, Kalinga potters in the Philippines or potters from Tuxtla in Mexico control the firing process through the assessment of the colour of the flame and the vessels within the firing structure. These assessments require great skills and are performed only by the most experienced potters of the group. Their conclusions regarding these parameters are considered as highly informative of the state of the firing (Banning, 2005; Morales, 2005; Rice, 1987; Skibo, 1992).

A temperature range between $500^{\circ}-700^{\circ} \mathrm{C}$ is enough to avoid the rehydration of the clay and eliminate its ability to become plastic. At the same time, at this range of temperature the ceramics also have some resistance to immersion in water, being able to retain their integrity and the ability to be reused (Albero, 2011a; Palamarczuk, 2004). As soon as the constitution water is removed from the clay minerals, the elasticity and the shrinkage of the paste are significantly reduced. A permanent bonding takes place then between clay particles, thus generating a waterproof material with certain mechanical properties that is suitable for its use as a ceramic container. Once this stage is reached, it is impossible to reintroduce water into the molecular structure of the clay minerals.

If the firing temperature increases up to $950^{\circ} \mathrm{C}$ the complete destruction of the crystalline structure of clay minerals occurs, which in a liquid phase begin to fuse together at their edges in a process known as sintering. At this point the recognition of the clay minerals is impossible while pottery with a very low porosity and heat resistant is obtained. The amount of glassy phase formed depends on the quantity 
of the phyllosilicates, as well as the duration and temperature reached during the pottery firing (Capel et al., 1982). In this way, clay minerals having potassium in their structure, such as illite, increase the presence of fluxes in the paste, thus favouring the sintering process. The high temperature minerals that usually emerge in the paste when phyllosilicates such as illite decompose are spinel (up to $1200^{\circ} \mathrm{C}$ ) and mullite, that appears due to the formation of glass from $1100^{\circ} \mathrm{C}$ (Bernal et al., 2003; Buxeda et al., 2002; Capel, 1983; Echallier, 1984; Jordán et al., 2008; Linares et al., 1983; Murad and Wagner, 1996; Rice, 1987; Worrall, 1975).

The physical consequences of the sintering process in the ceramic microstructure can be clearly seen through the analysis of the clay matrix in fresh pottery cross sections by means of scanning electron microscope using electron secondary images (Fig. 12.3). In this way, it is possible to observe how the formation of a glassy phase due to a more or less continuous sintering process originates a ceramic matrix with a microstructure in which clay minerals have smooth surfaces as well as soft and rounded melting points. These characteristics of the matrix refer to temperatures between $850^{\circ}$ and $1000^{\circ} \mathrm{C}$. In contrast, in other cases the matrix microstructure has clay sheets without evidences of sintering or that just show an early stage of sintering, thus suggesting a firing temperature below $800^{\circ} \mathrm{C}$ (Cuomo Di Caprio, 1985; Mainman, 1982).
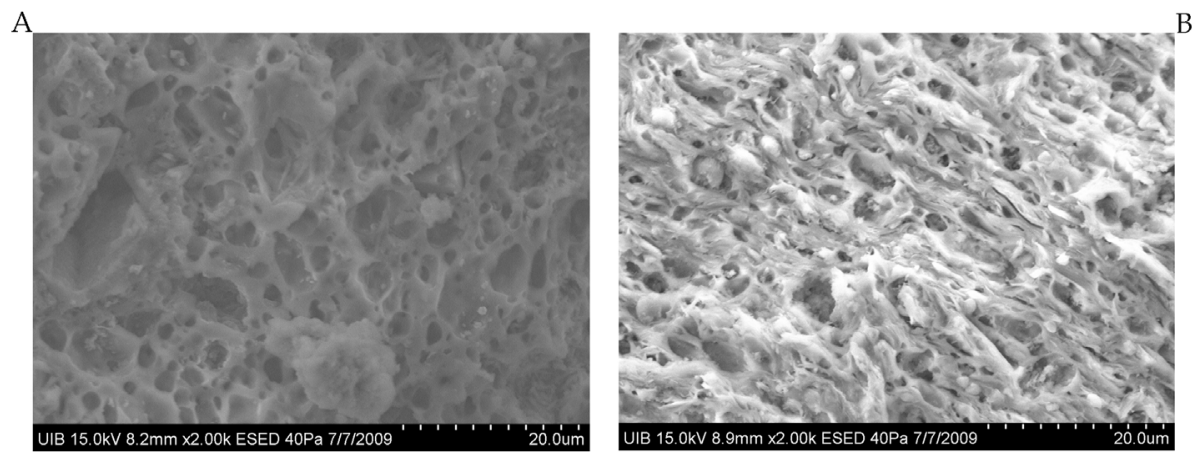

Figure 12.3: Secondary electron images (SEM-ESED) showing the matrix microstructure of two ceramics. A) Smooth surfaces and soft and rounded melting points in clay sheets from a pottery with high temperature mineral phases $\left(>850^{\circ} \mathrm{C}\right)$. B) Very early stage of sintering in the clay matrix of a pottery $\left(<800^{\circ} \mathrm{C}\right)$.

So far, we have assessed how the firing process affects the dehydration of the paste and alters the phyllosilicates present. However, the effects of pottery firing not only involve clay minerals but also the composition of the aplastic components present in the paste. In this way, attention should be paid to the more or less calcareous nature of the pottery and the type of tempers and inclusions present. Therefore, in the following sections we are going to approach briefly the thermal behaviour of three 
types of ceramic products that are widespread worldwide: calcareous pastes, noncalcareous pastes and pastes rich in organic matter.

\subsection{Calcareous Pastes}

In many pottery productions the main constraints occurring in the firing process are related to the use of calcareous clays and aplastic components formed by calcium carbonate (CaCO3) that provide very calcareous pastes. In these kind of pastes the degree of porosity of the pottery is increased during the firing (Cuomo di Caprio, 1985), thus forming vacuoles that are macroscopically observable. This increase in porosity is especially significant when the firing temperature is above $750^{\circ} \mathrm{C}$. As can be clearly seen in DTA-TGA thermal analysis (e.g., Albero, 2010) the decomposition of the carbonates in the ceramic body starts at $650^{\circ} \mathrm{C}$, while its total destruction takes place around $800^{\circ} \mathrm{C}$ (Fig. 12.4). This reaction causes an endothermic phase and a significant weight loss in the sample depending on the amount of calcium carbonate (e.g., calcite) present in the mixture.

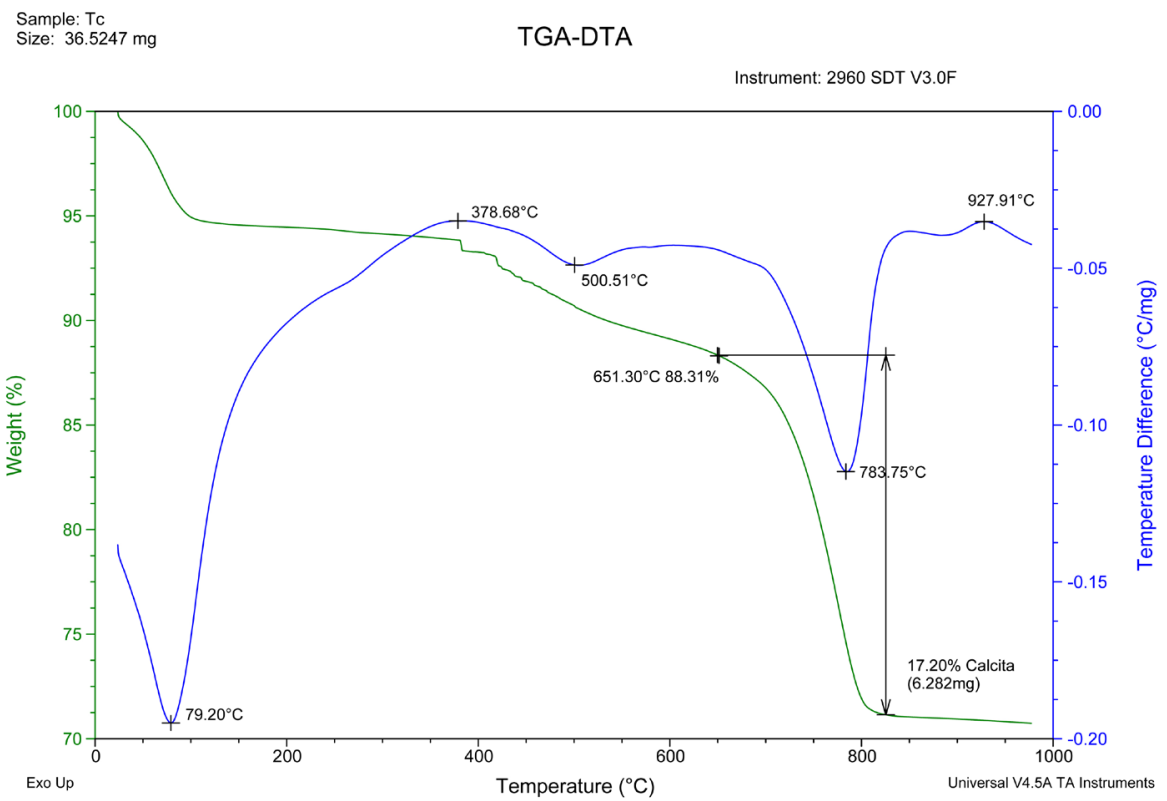

Figure 12.4: DTA-TGA analysis showing the thermometric behaviour of an experimental sample of calcareous clay tempered with spathic calcite. Note the presence of an endothermic peak and a noticeable weight loss in the sample between $700^{\circ}$ and $800^{\circ} \mathrm{C}$. 
Calcite is the most common pure calcium carbonate mineral found in pottery vessels. Moreover, this mineral is the main component in many materials that are usually present in archaeological ceramics such as limestone or shells, among many others. The thermal instability of calcite involves important constraints in ceramic production. Under conditions in which the calcium carbonate is subjected to heat until decomposition $\left(650^{\circ}-898^{\circ} \mathrm{C}\right)$, a very unstable phase known as calcium oxide takes place. This change of phase produces a significant stress in the pottery and, in consequence, may generate fractures. In addition, calcium oxide is hygroscopic, so it absorbs moisture from the atmosphere resulting in its hydrated form $\left(\mathrm{Ca}\left(\mathrm{OH}_{2}\right)\right)$. This hydration occurs immediately and increases the volume of the crystals, usually causing the collapse of the ceramic (Gibson and Woods, 1990; Rye, 1976). This process involves from the generation of cracks in the pottery as a result of the high tension to its total pulverization in less than 24 hours after being exposed to air humidity (Albero, 2011a). The extent of the damage depends on several factors such as the temperature achieved, the time of exposure to the highest temperature and the amount and size of the carbonates present in the paste. If the firing temperature is high enough and the pottery remains for a significant time at the highest temperature, calcite reacts completely and then the ceramic explodes. This process is more drastic with larger grain size carbonates and higher temperatures. Hence, the production of highly calcareous ceramics requires certain technical knowledge regarding the temperature, duration and atmosphere of the firing for the pottery production to be successful (Cuomo di Caprio, 1985; Drebushchak et al., 2005; Feathers, 1989; Hoard et al., 1995; Rice, 1987; Schiffer and Skibo, 1987; Shoval, 2003; Steponaitis, 1984).

Particle-size also influences the temperature at which carbonates such as calcite react. Thus, the decomposition of these components occurs at higher temperatures in archaeological ceramics that have a coarser grain-size. During heating, the coarsest grains placed in the core of the paste may react in $\mathrm{CaO}$ masses that crack. However, these grains still unaltered at temperatures at which, theoretically, should have been incorporated to high temperature mineral phases. This parameter along with other variables, such as the degree of crystallinity, explain the wide range of temperatures $\left(500^{\circ}-900^{\circ} \mathrm{C}\right)$ in which this reaction may take place ${ }^{16}$. Therefore, the size of calcite particles, along with the duration of the firing (Olaetxea, 2000), determine the formation of high temperature phases. High-temperature minerals are more likely to be formed from $750^{\circ} \mathrm{C}$ if the calcite grain size is small, since the calcium ions of the carbonates are diffused quickly towards the particles of quartz, feldspars and clay minerals. If the calcite grains are coarse their total decomposition takes place at less

16 This is a fact stated in the extensive literature available about the decomposition temperature of calcium carbonate (e.g., Bronitsky and Hamer, 1986; Capel, 1983; Drebushchak et al., 2005; Gibson and Woods, 1990; Hoard et al., 1995; Linares et al., 1983; Mahmoudi et al., 2008; Maritan et al., 2006, 2007; Palomar, 2005; Papadopoulou et al., 2006; Rice, 1987; Rye, 1976; Shoval et al., 2006). 
than $900^{\circ} \mathrm{C}$ (Albero, 2010, 2011a). Regardless, the type of calcite is also involved in this process, thus micritic calcite begins to decompose at lower temperatures than spathic or micro-spathic calcite (Olaetxea, 2000).

A coarse particle-size can avoid certain harmful reactions in the paste, but large amounts of coarse calcite grains also generate severe fractures during the firing. Thus, Bronitsky and Hamer (1986) established a positive correlation between the size of the inclusions and the risk of thermal and mechanical fracture during this stage of the chaîne opératoire. J. Capel (1986) has confirmed through experimental research that the frequency and size of the calcite is a decisive factor in this process. Thus, the risk of fracture increases significantly from a frequency of 20-30\% and a size exceeding $2 \mathrm{~mm}$. In this sense, it is desirable in technical terms that the carbonates had a particle-size smaller than $1 \mathrm{~mm}$, as the particles would be fine enough to minimise the generation and propagation of fractures due to differential thermal expansion. In any case, is also appropriate that the grains were relatively coarse in order to delay their reaction.

As we have seen, firing pottery at temperatures above $800^{\circ} \mathrm{C}$ promotes the decomposition of carbonates. This process also includes the microfossils naturally occurring in the sediments as well as calcareous rock fragments such as biosparite or biomicrite. Since these carbonated components are usually formed by calcite or aragonite, they are also affected by this process of decomposition. Microfossils formed by aragonite react around $500^{\circ} \mathrm{C}$, when this mineral is transformed into calcite and subsequently decompose at temperatures below $750-800^{\circ} \mathrm{C}$ (Quinn, 1999; Quinn and Day, 2007a). The same occurs with dolomitic rocks: after reaching $750^{\circ} \mathrm{C}$, the crystalline structure of dolomite is transformed completely to calcite (Ozao et al., 1991). In this sense, the presence of calcareous microfossils and dolomite along with the absence of high temperature minerals in the vessels is evidence of firing temperatures below $800^{\circ} \mathrm{C}$.

Calcium carbonates present in the paste react with clay minerals giving place to the crystallization of calcium-silicates and alumina-silicates of high temperature. Thus, high temperature minerals such as gehlenite, diopside, hematite, wollastonite or anorthite are usually formed. At the same time, the emergence of $\mathrm{CO}_{2}$ from the reaction of the calcium carbonate causes the development of a cellular microstructure in the ceramic matrix. If the temperature increases until $1050^{\circ} \mathrm{C}$, the gehlenite and hematite peaks reduce their intensity while peaks of pyroxene and plagioclases gain intensity (Buxeda et al., 2002; Capel, 1983; Jordán et al., 2008; Linares et al., 1983; Mainman, 1982; Murad and Wagner, 1996; Ortega et al., 2005; Riccardi et al., 1999; Shoval et al., 2006).

During pottery firing the calcareous component of the paste, especially if it is related to micritic calcite, also affects the colour of the vessels. In this sense, highly calcareous ceramics fired in oxidising atmosphere tend to develop light pink or cream colours depending on the amount of calcite existing in the paste. This coloration is originated because the iron oxide particles decrease in size when they are exposed to temperatures exceeding $700^{\circ} \mathrm{C}$ and the presence of calcite in the clay impedes up to 800 ${ }^{\circ} \mathrm{C}$ the formation of hematite crystals. Furthermore, highly calcareous ceramics fired in a reducing atmosphere tend to turn into pale grey and even white colours depending on 
the amount of calcium present in the paste. Again, calcite prevents the reduction of iron oxides such as magnetite that provide a black-coloured fabric (Capel et al., 2006; Cuomo di Caprio, 1985; Maniatis, 2002; Molera et al., 1998; Morales, 2005).

The differential thermal expansion that is characteristic of each component of the paste is one of the physical processes that may cause severe failures during pottery firing. So, many minerals expand their crystallographic cells when heated and the expansion rate can be expressed in terms of volume expansion coefficient per heat unit increase (Rye, 1976; Steponaitis, 1984). The coefficient of thermal expansion of minerals such as calcite (Rosenholtz and Smith, 1949) and several clay minerals (Mackinstry, 1965; Searle and Grimshaw, 1959) were established by mineralogists long time ago.

Some scholars (Gibson and Woods, 1990) stated that in firings below $800^{\circ} \mathrm{C}$ the dilatometric changes that the paste suffers are of small significance, being the volumetric changes in the clay minerals more important in ceramic bodies fired above $900^{\circ} \mathrm{C}$. Thus, when the pottery is fired at low temperatures the ceramic body is slightly expanded and becomes more porous, affecting the vessel weight rather than its volume. If a given mineral has a coefficient of thermal expansion greater than the matrix in which it is placed its particles will expand faster than the clay, resulting in a great stress in the vessel during the firing process. When the difference between the coefficient of thermal expansion of the aplastic components and the clay matrix exceeds certain limits multiple fractures, usually microscopic, are generated and propagated in the ceramics. Therefore, the firing temperature as well as the nature and size of the inclusions and tempers existing in the paste are key factors to be fully considered in this physical process. In the case of highly calcareous pastes this potential problem almost disappears, since calcite has a low coefficient of thermal expansion which is virtually identical to low fired clays (Hoard et al., 1995; Rye, 1976; Shoval et al., 2006; Steponaitis, 1984; West, 1992).

Prehistoric potters were able to develop a number of criteria that would act as empirical evidence when performing complex technical operations, such as the firing of calcareous pottery. In fact, individuals could have been acquainted with these materials, both in relation to the manufacturing process and the final product. There are several parameters to be used in this regard. For example, the weight of the pottery may indicate a proper firing of ceramics, since the decomposition of calcite entails a substantial reduction in the weight of the vessel which would have been evident for the potters.

The physicochemical process associated with the decomposition of calcium carbonate into calcium oxide has been known at least since the Neolithic period, when the earliest evidences of the production of lime mortars are documented (Shoval et al., 2006). In antiquity, potters themselves could have developed the production of calcium oxide on a small scale according to their needs and establish a close relationship with the calcareous materials and their behaviour. Therefore, a conventional wisdom could have developed regarding the dilatometric and hygroscopic behaviour of calcium oxide. Moreover, the decomposition of calcium 
carbonate during firing could have been also known from empirical observations based on the colour of the smoke and the stones during firing (Albero et al., 2010).

Archaeologically it is possible to identify the reaction of the carbonates from the presence of high temperature minerals such as gehlenite in the X-ray diffractograms (Fig. 12.5). Also, sometimes thermal alterations in the carbonates can be identified through petrographic microscope (Tschegg et al., 2009). These thermal alterations result from a deterioration process that comprises various stages that start from $550^{\circ} \mathrm{C}$ (Riccardi et al., 1999) and are visually identifiable, at least in the case of spathic calcite (Risch and Gomez-Gras, 2003). The thermal alteration of the carbonates is usually more evident in the vessel margins, since the area closest to the surfaces of the pottery is the most exposed to the highest temperatures (Fig. 12.6).

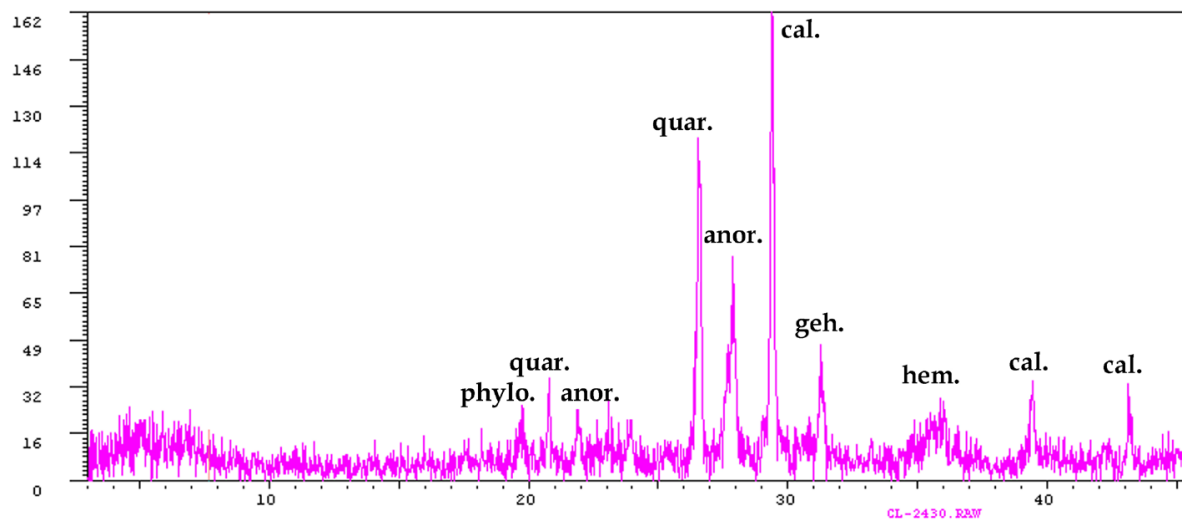

Figure 12.5: XRPD diffractogram showing high temperature phases such as gehlenite, anorthite or hematite identified in a calcareous ceramic.
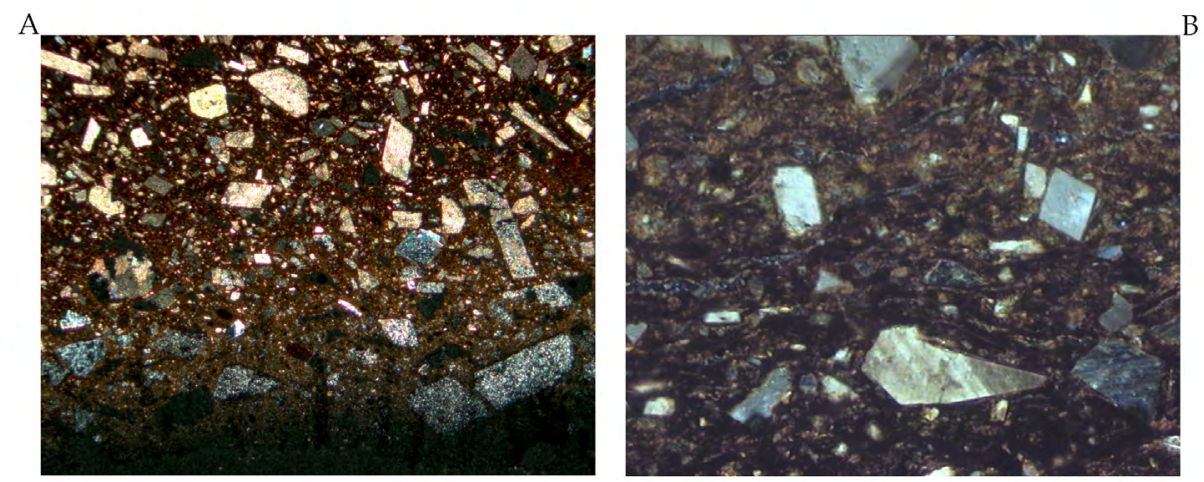

Figure 12.6: Thin section photomicrographs taken with cross polarised light showing A) calcite crystals supra-altered in the external margin of the vessel and altered crystals in the core of the section (Image width $=2.7 \mathrm{~mm}$ ). B) Translucent and unaltered spathic calcite crystals (Image width $=1.1 \mathrm{~mm}$ ). 


\subsection{Pastes Rich in Organic Matter}

The effects of the combustion of the organic matter present in the paste during the firing process have been addressed in archaeometry through experimental research (Hodges, 1962; Johnson et al., 1988; Maritan et al., 2006; Schiffer and Skibo, 1987). Firing pastes with abundant organic matter produces gaseous components that are released into the atmosphere. These volatiles are, among others, water vapour and oxygen as well as, depending on the type of firing atmosphere, anhydride or carbon monoxide and carbon dioxide which mainly comes from the organic matter existing in the paste. In this situation, the degree of porosity and thickness of the pottery influences both the release and absorption of gases between the paste and the external atmosphere.

The organic components of the paste, either the humus naturally present in the clay or the organic matter intentionally added by the potters, can be completely combusted during firing, thus greatly increasing apparent porosity. These organic components are decomposed between $200^{\circ}-800^{\circ} \mathrm{C}$ depending on the type of material and the flow of oxygen in the paste. The combustion of organic matter takes place first in the vessel's margins and eventually in the ceramic core, usually leaving imprints, or even sometimes charred organic fibres, in the fabric. Thus, significant increase in paste porosity after the firing process reduces dangerously the hardness of the fired vessels (Cuomo Di Caprio, 1985; Gibson and Woods, 1990; Livingstone-Smith, 2007; Morales, 2005; Rice, 1987; Smith and Trinkley, 2006; Szákmany and Starnini, 2007; Toledo et al., 2004; West, 1992).

The circulation of gases from the core towards the vessel margins prevents the oxidation of the paste, generating poorly oxidized margins and reduced cores that result in sandwich or cuore nero structures. Therefore, the decomposition of organic matter increases the amount of carbon in the paste, affecting the quality and colour of the pottery. The effects of this process in the development of reducing atmospheres are readily observable in the blackish colour of the clay matrix surrounding the pores left by the combustion of organic matter. Thus, in this type of paste the iron content does not determine the colour of the fired pottery until the organic matter has been completely burnt. In short, a ceramic with abundant organic matter and some closed pores can keep the paste under a reduced firing atmosphere. These reduction conditions occur even in firing structures in which oxidising conditions prevail, especially if the organic matter has not completely decomposed (Banning, 2005; Cuomo Di Caprio, 1985; Echallier, 1984; Hodges, 1962; Husein Malkawy et al., 1999; Maritan et al., 2006; Nodari et al., 2004; Orton et al., 1993; Rice, 1987; Tite, 2008).

The decomposition of organic matter during the firing process involves a decrease in the total weight of the vessel and generates exothermic phases between $350^{\circ}$ and $450^{\circ} \mathrm{C}$ related to its oxidation (Fig. 12.7). However, as the weight loss observed in this process is low, the stress produced in the paste by the combustion is not dangerous enough to damage the pottery (Albero, 2010; Mahmoudi et al., 2008; Maritan et al., 2006; Maritan et al., 2007; Murad and Wagner, 1996; Souza et al., 2005). 


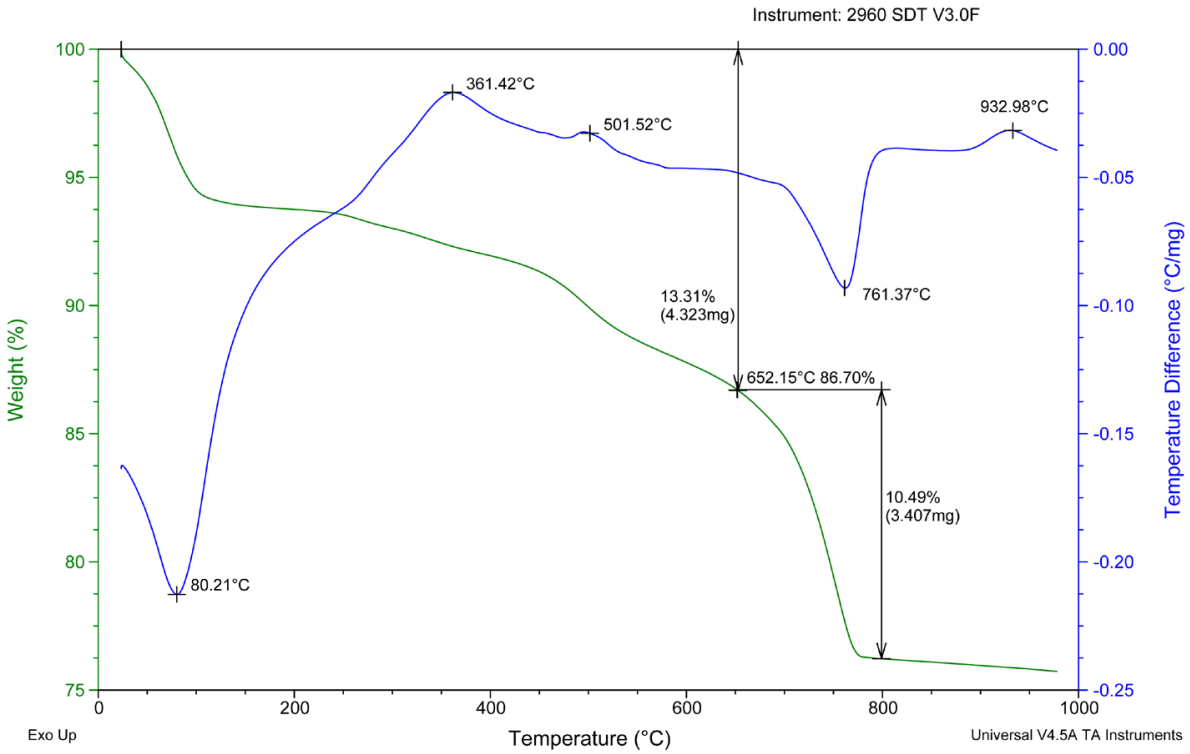

Figure 12.7: DTA-TGA analysis showing the thermometric behaviour of an experimental sample of calcareous clay tempered with $20 \%$ (in volume) of organic matter (Poaceae). Note the presence of two exothermic peaks at $362^{\circ} \mathrm{C}$ and $503^{\circ} \mathrm{C}$ related to the oxidation of the organic matter.

The combustion of organic matter also generates heat in the paste, thus helping to fire the pottery. The burning of this component produces a pyrolysis process in which the material decomposes by heating in the absence of oxygen (Johnson et al., 1988). Thus, the flame remains active even in environments with high amounts of $\mathrm{CO}_{2}$. Rapid firings are more appropriate for pastes rich in organic matter, since these pastes have a higher rate of fractures when they are slowly fired (Hodges, 1962; Livingstone-Smith, 2007).

These experimental research along with the observations performed by other archaeological and ethnographic studies on ceramic pastes rich in organic matter (Albero, 2011a; García Rosselló et al., 2011; Gibson and Woods, 1990; Szákmany and Starnini, 2007) allow us to state that the presence of abundant organic temper, either graphitized or partially conserved in the fabrics (Fig. 12.8), evidences a low firing temperature $\left(550^{\circ}-650^{\circ} \mathrm{C}\right)$, a short time of exposure to temperatures above $700^{\circ} \mathrm{C}$, a quick increase in temperature and a short firing cycle. The graphitization process takes place, depending on the texture and the type of plants existing in the paste, between $200^{\circ}-500^{\circ} \mathrm{C}$ and $700^{\circ}-800^{\circ} \mathrm{C}$, when the total combustion of the organic matter present in the pottery occurs. 
Furthermore, the abundant presence of organic matter which was not volatilised in the pottery is related to a rapid heating rate in the range $400^{\circ}-700^{\circ} \mathrm{C}$, when its combustion is almost finished (Morales, 2005). Hence, these features may be related to ceramics fired by means of rapid firings at low temperatures. The use of organic matter as temper in combination with this type of firing procedures generates a ceramic body minimally fired, since the paste also incorporates some of the fuel used to provide heat during the process. This strategy helps increase the time of exposure at the highest temperatures in open firings in which fuel is quickly consumed (Palomar, 2005).

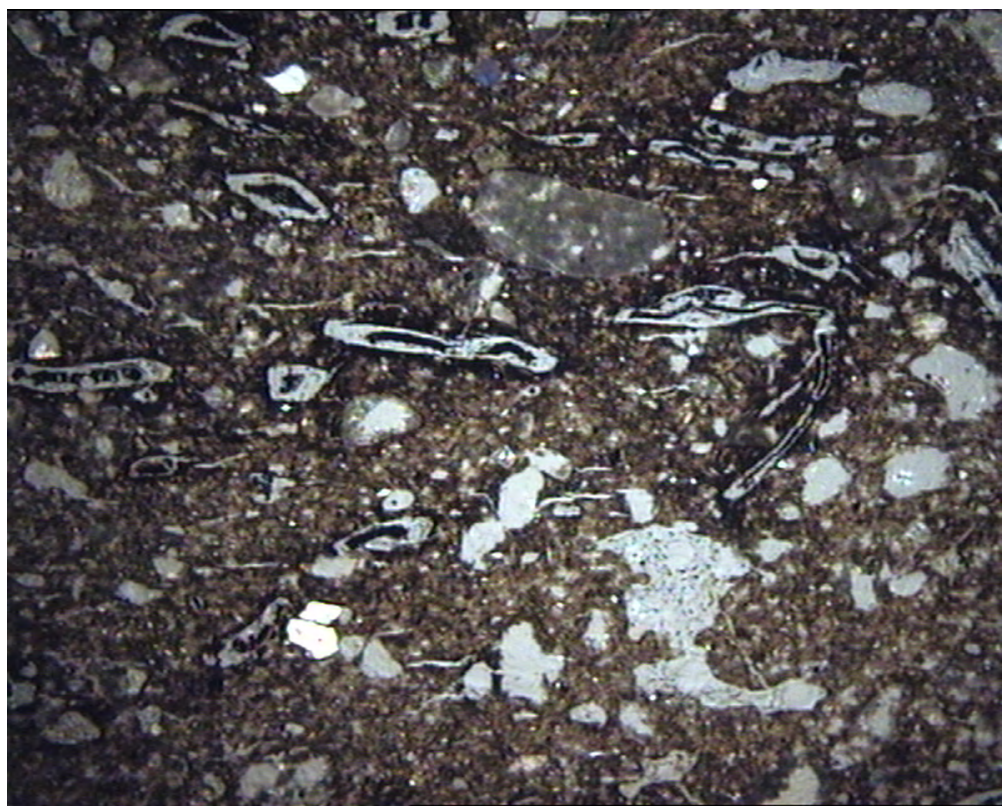

Figure 12.8: Thin section photomicrograph taken in plane polarised light showing graphitized organic matter added to the paste in a pottery. Note that the firing process in this fabric results in significant increase in porosity (Image width $=4.6 \mathrm{~mm}$ ).

\subsection{Non-calcareous Pastes}

Quartz is usually one of the most abundant minerals in non-calcareous pastes rich in silica. Regarding its physical properties, this mineral is highly stable and thermally resistant. The influence of quartz in the mineralogical changes resulting in the paste during firing is directly related to its grain-size and the temperature achieved. Thus, firing temperature causes different effects in the paste depending on the particle size of the quartz crystals. While coarse quartz particles reduce the shrinkage of 
the paste during the drying process, fine grains promote the formation of a glassy phase due to an easier fusion. Hence, the latter grain-size favours the emergence of high temperature minerals. From $950^{\circ} \mathrm{C}$ quartz acts as a flux and is transformed into cristobalite. As already seen, highly siliceous and border calcareous pastes usually exhibit fewer changes than calcareous pastes in their microstructure during the firing process. This stability also involves a reduced development of high temperature mineral phases. However, the microstructure of siliceous materials is denser due to the formation of a glassy phase at certain temperatures (Cuomo Di Caprio, 1985; Hein et al., 2009; Linares et al., 1983; Morales, 2005; Velde and Druc, 1999; West, 1992).

In any case, there are some structural changes in the quartz crystals during firing that result in expansion and shrinkage processes at about $573^{\circ} \mathrm{C}$. It is at this temperature when quartz $\alpha$ turns to quartz $\beta$, thus changing its rhombohedral crystalline structure by a hexagonal crystal system. This process is retroactive and when the progressive cooling of the pottery takes place the quartz recovers its initial volume, sometimes leaving a pore in the perimeter of the particles. If the cooling process is not progressive some grains tend to break, originating small shards of quartz with conchoidal fracture in the fabrics. In this sense, quartz has a thermal expansion coefficient much higher than the clay minerals, so that, its use under poorly controlled conditions may result in fractures in the vessels. These fractures are more severe when this mineral is abundant in the paste and has a coarser grain-size (Cuomo Di Caprio, 1985; García Orellana et al., 2001; Rye, 1976). Thus, except in some specific productions, it is technically preferable to use pastes in which the quartz is present in low frequency and fine particle-size.

Finally, in reference to pottery vessels that have high amount of feldspars we should highlight that, like quartz, this group of minerals is relatively immune to the effects of heat. However, feldspars (especially alkali feldspars) act as an effective flux within the paste, contributing to the formation of a glassy phase in the pottery when decomposed at $1000-1100{ }^{\circ} \mathrm{C}$. Thus, alkali ions promote the formation of a vitreous structure in the paste while inhibiting the creation of high temperature mineral phases, preventing the development of crystals (Linares et al., 1983).

\subsection{Firing Atmosphere}

Different firing procedures may involve diverse temperatures, durations and firing atmospheres. These differences are closely related to the use of certain fuels and firing structures. Unfortunately, it is often very difficult to identify firing areas as well as their associated structures (if any) and remains in the prehistoric archaeological record. Thus, this lack of evidence is one of the main problems researchers have to face when studying the structures and fuels used in prehistoric pottery firing. 
Nevertheless, given its widespread use in pre-industrial societies as a source of heat, it can be assumed that vegetable fuels such as wood was the most commonly used in ancient pottery productions. However, we also have to accept that further knowledge regarding the management of vegetable raw materials in prehistory requires necessarily of anthracological and pollen analysis. These studies are able to report the possibilities of the natural environment and the management ancient communities made of the biotic resources available, including those potentially related to pottery production.

In short, due to these constraints the firing process can usually only be addressed through the conclusions obtained from the study of the ceramic fabrics themselves. Therefore, resorting to ethnographic and experimental information is essential in order to make assumptions on this phase of the chaîne opératoire. Ancillary sources of information allow us to make hypotheses that relate the features of the pottery to the several factors involved in the firing process. In this sense, many ethnoarchaeometric and ethnoarchaeological research has been developed in order to properly approach firing procedures and provide some reflection regarding the way the firing process is usually interpreted by archaeologists. For instance, the ethnographic works that have focused on the creation of a reference collection with the aim of interpreting the technological features of the pottery in relation to different kinds of firing structures and procedures can be highlighted (García Rosselló, 2008; Gelbert, 2003; Gosselain, 1992b; Livingstone-Smith, 2001, 2007; Nicholson and Patterson, 1985; Pool, 2000; Sillar, 2000).

One aspect that is essential to address regarding pottery firing, along with temperature and the duration of the process, is the firing atmosphere. The best way to approach the firing atmosphere is analysing the chromatic transitions observed in the ceramic cross sections. The study of colour transitions in the pottery section is much more effective by means of macroscopic analysis since it allows us to observe the whole pottery vessel. Therefore, the results obtained through this method regarding the atmospheres prevailing in the firing process have great significance (García Rosselló and Calvo, 2006; García Rosselló et al., 2011).

In order to address the kind of firing structures and the firing atmospheres that ancient potters could have used, we can complement the features of the fabric recorded by archaeometric techniques along with optical observations of the chromatic traits in the ceramic cross section. Observations performed at low magnifications record a wide range of possibilities regarding colour transitions:

- $\quad$ R: Reducing atmosphere.

- 0: Oxidising atmosphere.

- o-R-o: Reduced core and thin oxidised margins.

- 0-r-0: Oxidised margins and thin reduced core.

- O-r: Oxidised external margin and core; thinly reduced inner margin.

- o-R: Thinly oxidised external margin; reduced core and internal margin. 
- $\quad$ R-o: Reduced external margin and core; thinly oxidised internal margin.

- r-0: Thinly reduced external margin and core, oxidised core and internal margin.

- R-O: Reduced external margin and core; oxidised core and internal margin.

- O-R: Oxidised external margin and core; reduced core and internal margin.

- O-R-o: Oxidised external margin, reduced core and thinly oxidised internal margin.

- o-R-0: Thinly oxidised external margin, reduced core and oxidised internal margin.

- O-R-0: Oxidised internal and external margins and reduced core.

Many studies have addressed prehistoric pottery firing and its relationship with various firing structures and atmospheres. These studies recorded that several strategies may be used to change a reducing atmosphere to an oxidising one and vice versa. Firing atmosphere is a very complex parameter that involves many variables, especially in the case of a reducing atmosphere, and influences certain attributes of the vessels, such as the final colour (Cuomo Di Caprio, 1985; Dawson and Kent, 1987; Livingstone-Smith, 2007; Reid, 2001).

Many prehistoric vessels usually show heterogeneity of colour on their surfaces, evidencing that the firing was carried out in structures in which there was no uniform air circulation and heat distribution. Moreover, the existence of black patches on the surfaces of the vessels points to the use of structures in which fire and fuel were in contact with the pottery (García Rosselló and Calvo, 2006; García Rosselló et al., 2011).

Pottery firings that usually do not reach $900^{\circ} \mathrm{C}$, and in which oxygen flow is irregular and in consequence completely reduced or oxidised atmospheres are very difficult to achieve, are the product of both bonfires and pit firings (Spataro, 2002; Van As, 1984). As previously said, both pits and open firings are not entirely uniform, especially when most of the fuel is consumed and the oxygen invades the firing structure. Thus, there are a high number of factors in these firing structures that the potters do not control. Regardless of the manufacturing process, this low control of the pottery firing determines the patchy and heterogeneous colour frequently observed on the surfaces of many prehistoric ceramics.

Such firings usually have a faster heating rate compared with kilns and provide enough temperature $\left(500^{\circ}-900^{\circ} \mathrm{C}\right)$ to generate the dehydroxylation of clay minerals, thus producing ceramics with a certain degree of hardness and which are waterproof. Normally if the pottery survives to the firing process it remains relatively unaffected by direct contact with a domestic hearth. Such domestic structures are usually used to cook over coals rather than flames and reach a low temperature range, normally between $300^{\circ}$ and $500^{\circ} \mathrm{C}$ (Gibson and Woods, 1990). 
a) Closed Firings

The pottery fired in this type of structure is characterized by dark surface colours, although in most cases they can also be slightly oxidised, thus showing red patches. However, when the pottery is observed in cross section, the core appears dark and usually has no marked differences with the outer margins of the vessel. To produce this chromatic arrangement in the core and margins of vessels manufactured with pastes poor in organic matter a highly reducing atmosphere is required along the firing. Therefore, the potters pay continuous attention to the firing to succeed in the reduction process. Potters can build specific types of features in order to encourage the absence of oxygen within the firing structure. Moreover, they can saturate the firing atmosphere with smoke originated from the combustion of fuel, especially if green and humid wood is used. Thus, reducing atmospheres are attained by using closed firings and continuously adding fuel, since in this way the circulation of air within the structure is impeded (Barley, 1994; García Rosselló and Calvo, 2006; Reid, 2001). In comparison to an oxidising atmosphere, the use of a reducing environment increases the reaction temperature of the components of the paste by 50ㄷ (Maritan et al., 2006).

These ceramic features fit well with some experimental closed firings (e.g., Gasull et al., 1984; Waldren, 1991) developed in both pit firing and bonfire sealed with mud using relatively slow heating rates and long cooling times. The maximum temperature achieved in bonfires sealed with mud was around $850^{\circ} \mathrm{C}$, while pit firings carried out in a windy day reached $1000^{\circ} \mathrm{C}$. As noted before, this range of temperatures may entail severe consequences in certain pottery productions, such as high calcareous pastes. The entry of oxygen within the structures occurs during the last stage of the firing process, when the fuel is consumed and starts the cooling period. Thus, the emergence of air inside the firing structure oxidises the ceramic surfaces as well as, in some cases, the vessel margins, which develop a thin red layer when seen in cross section.

In a reducing atmosphere, the gas released during firing tends to bond with the oxygen atoms of some ceramic components, thus explaining the great colour variability that is usually observed in the surfaces of the pottery but not in the core. Reduction firings are very difficult to achieve, even using modern laboratory techniques. The main reducing agent in the firing is the carbon monoxide released from the organic matter present in the paste and the fuel used. In this sense, many potter communities that aim to achieve reducing atmospheres prefer to build sealed and non-permanent structures that are dismantled after the cooling period and once the vessels are removed (Dawson and Kent, 1984, 1985; García Rosselló and Calvo, 2006; Livingstone-Smith, 2007). As documented in Tuxtla (Mexico), potters can build proper structures to carry out closed firings in just a couple of hours (Pool, 2000).

However, as pointed out by experimental studies, despite the influence of particular types of structures in the firing atmosphere and the colour of the vessels (García Rosselló and Calvo, 2006), we cannot forget that the main factor that makes it possible to achieve a reduced fabric is the potter's skill. Thus, potters can consciously 
vary the technological choices they make along the firing procedure in order to obtain pottery vessels with specific characteristics (Dawson and Kent, 1985).

\section{b) Open Firings}

Vessels fired in open structures are characterized by the presence of pale and reddish surfaces. However, rarely is fully oxidized pottery achieved, since it is common to find dark patches on the surfaces derived from the contact with the fuel (García Rossello and Calvo, 2006). In this sense, Livingstone-Smith $(2001,2007)$ has distinguished from the thermometric behaviour of 80 ethnographic firings several types of structures that generate ceramics with this range of colour (e.g., bonfires, depressions in the ground, poorly insulated open firings and ceramic kilns). Most of the firings recorded were characterised, in general, by durations shorter than one hour and a heating rate that may be higher than $40^{\circ} \mathrm{C} / \mathrm{min}$.

In most of these structures both firing temperature and atmosphere can be highly variable, either along the firing process and the different parts of the structure or in the same vessel (Gosselain, 1992b; Livingstone-Smith, 2001; Maggetti et al., 2011; Nicholson and Patterson, 1989). However, open firings provide quick heating rates up to the maximum temperature, which can be attained in less than half an hour. Many open firings in which the maximum temperature is achieved in less than 20 minutes are recorded (Hoard et al., 1995; Hodges, 1962; Skibo, 1992). The firing procedures used by Kusasi and Konkomba potters from north-east Ghana (Fig. 12.9) are good examples of a quick rise in temperature, since the maximum temperature is reached in the first minutes of the firing process (Calvo et al., 2013).
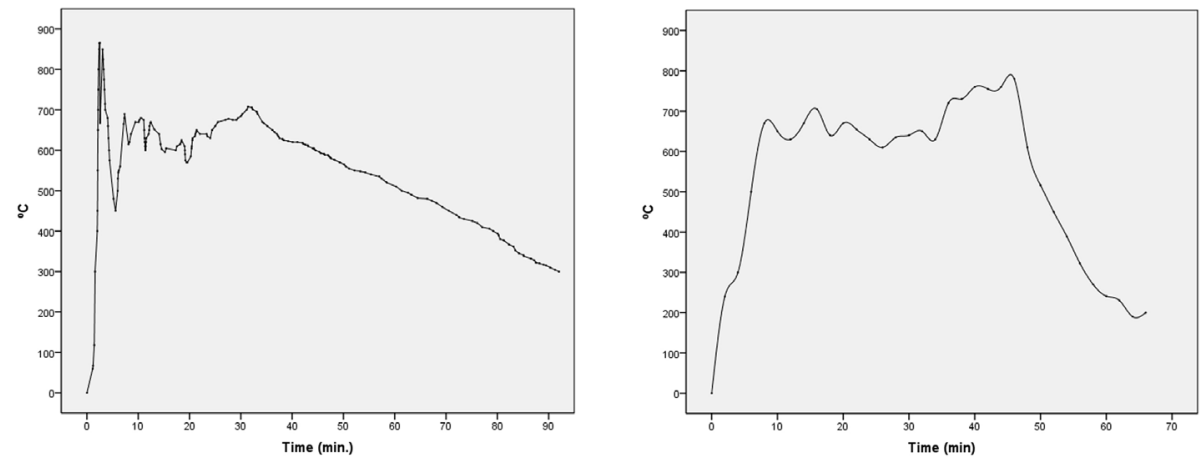

Figure 12.9: Time-temperature curves of open firings recorded in the Upper East and Northern regions of Ghana (after Calvo et al., 2013). A) Konkomba bonfire without any insulation. B) Kusasi firing with insulation construction covered with broken ceramics. 
Once the maximum temperature is raised, normally ranging from $500^{\circ}$ to $900^{\circ} \mathrm{C}$, it is maintained for a very short time (Gibson and Woods, 1990; Maggetti et al., 2011; Tite, 1999, 2008). As described by A. Livingstone-Smith (2007), the exposure to maximum temperature is often kept for less than nine minutes in the case of bonfires, depressions in the ground and poorly insulated open firings. Regardless of the type of structure used, the time of exposure at temperatures above $700^{\circ} \mathrm{C}$ is usually minimised and even non-existent. This is the case, for instance, of the domestic pottery made in Cameroon (Gosselain et al., 1996) and Philippines, which use bonfires that have short duration. In these cases the scale of production is low, for their own use, so that only between 6 and 20 vessels of a varied typology are simultaneously fired (Skibo, 1992; Van der Leeuw, 1984).

In this sense, it should be noted that the use of an oxidising atmosphere ensures optimum combustion conditions during pottery firing (Morales, 2005). However, the quickly reached heating rates mentioned above are only feasible in coarse pastes, such as the ones usually found in prehistoric ceramics. Thus, this quick increase in temperature during firing is not recommended for fine-textured pastes, such as the ones typically used to produce wheel-made pottery. Fine pastes like these contain high amounts of pore water and must be fired using slow heating rates in order to properly release the water vapour contained in the paste and avoid the collapse of the pottery. In any case, firing structures such as kilns are quite versatile and allow firing both fine and coarse pastes. Coarse-textured pottery has more possibilities to withstand quick heating rates, although there is still a high risk of cracking due to the evaporation of volatiles. It should be highlighted, therefore, that there was a need for coarse pastes in many prehistoric productions, since pottery vessels had to be able to resist firing procedures, such as the use of open firings characterised by fast heating rates (Tite, 1999, 2008).

Thus, potteries with low frequency of aplastic components fired with this latter procedure often have significant defects, such as alterations in their shape and size. These alterations are associated with a deformation of the surfaces, the angles and rims of the vessels, causing the loss of symmetry. These problems are also related to poor grinding and mixing of raw materials during the preparation of the paste that result in an heterogeneous composition due to the varied arrangement of the components in the matrix. This disposition involves, in turn, an irregular distribution of the moisture remaining in the pottery when it is introduced into the firing structure. Thus, deformation occurs as the consequence of a more intense and fast dehydration of certain parts of the pottery. In this sense, it is advisable to control wall thickness, especially in those areas of the vessels that are most susceptible to suffer cracks, as the rims (Morales, 2005).

Open firings that have short duration and low temperature leave little archaeological evidence, especially if the structure is cleaned after each use. Moreover, the sediment surrounding bonfires or pit firings is usually little affected. Further difficulty lies in distinguishing between conventional household fireplaces 
and pottery firing structures. This is a complex aspect since there are cases, for example in Nicaragua (Palomar, 2009), in which domestic hearths are also used to fire pottery. As Gibson and Woods (1990) have pointed out, it is necessary to develop further ethnoarchaeological and experimental research in order to solve these problems and approach the material record related to small-scale pottery firings. These frameworks may be very useful for identifying pottery firing structures and production areas that have gone unnoticed in the course of many archaeological excavations.

In addition to all the key aspects explained above regarding the use of open firings, an exception should be highlighted in which the use of such structures does not necessarily lead to oxidised sections and surfaces in the pottery. Ethnoarchaeological studies have demonstrated that pastes rich in organic matter may result in a chromatic range strongly related to reduced atmospheres, even if the pottery is fired in open structures. In these types of pastes and firing procedures, the pottery sections are fully reduced or only have thinly oxidised margins as well as pale patches on the surfaces. These features have been observed, for instance, in Krumiria (Tunisia) in ceramic assemblages fired in open firings. Potters from this area use leaves and cow dung as fuel in order to fire pastes rich in humus contents. The firing is finished in only 30 minutes and, after this process, the vessels have black cores and light coloured margins of a variable thickness (García Rosselló et al., 2011).

Experimental research undertaken with pastes rich in organic matter (Gibson and Woods, 1990; Hodges, 1962; Maritan et al., 2006; Nodari et al., 2004) has also reported that it is common to obtain blackened cores in oxidising atmospheres. Dark cores, especially present in the thickest walls, result from a reduced firing atmosphere that differs from the general oxidising atmosphere prevailing in the surfaces of the vessel. Therefore, reducing conditions take place in the core of pastes rich in organic matter, thus delaying the oxidation process. In these reducing atmospheres, the high amount of $\mathrm{CO}_{2}$ present in the firing at $650^{\circ} \mathrm{C}$ inhibits the loss of carbon from the organic matter. Carbon is released more slowly, so that, it is common to find charred organic components in the cores of pottery fired at low temperatures, in short firings and oxidising atmosphere. The amount of $\mathrm{CO}_{2}$ and therefore the reducing effects can be increased if wet organic matter is used to temper the vessels (Cuomo Di Caprio, 1985).

In short, pastes rich in organic matter do not necessarily require closed firings to develop reducing atmospheres inside the walls of the vessels. Hence, in these kinds of pastes we have to consider the open or closed nature of the structures employed in the firing and the way they relate to the chromatic distribution on the whole vessel. Moreover, in fabrics with graphitized organic matter and thinly oxidised vessel margins we can assume the use of low temperatures as well as short and open firings. 
Hodges (1962) stated on the basis of experimental research a high fracture index in pastes with high amounts of organic matter and fired using slow heating rates. However, other experimental studies (Schiffer and Skibo, 1987) also evidence that these types of pastes provide worse results than others rich in mineral aplastic components when they are fired by means of fast heating rates. The higher failure rate is related to the sudden and rapid loss of pore water from the paste in the form of water vapour, thus causing severe cracks and deformations in the pottery. According to these authors, this constraint can be overcome by preheating the ceramic or increasing slowly the temperature in the earlier stages of the firing process. 